inhibition at the level of motor system excitability. (Moll GH, Heinrich H, Trott GE, Wirth S, Bock N, Rothenberger A. Children with comorbid attention-deficithyperactivity disorder and tic disorder: Evidence for additive inhibitory deficits within the motor system. Ann Neurol March 2001;49:393-396). (Respond: Prof Rothenberger, von-Siebold-Str 5, D-37075 Gottingen, Germany).

COMMENT. Children with comorbid ADHD and TD have additive deficits in motor system inhibition, involving both cortical motor mechanisms and the sensorimotor circuit. This finding is thought to be in line with neuropsychological data suggesting most severe impairments of motor inhibition in ADHD combined with TD.

Motivational effects on inhibitory control in children with ADHD. Lowered inhibitory control in children with ADHD is attributed to low motivational incentive in a study of 33 children using a stop-signal task, at the University of Essen, Germany. (Slusarek $M$ et al. I Am Acad Child Adolesc Psychiatry March 2001;40:355-363). Under conditions of low incentives, children with ADHD were less able to inhibit reactions and had longer stop-signal reaction times. With high incentives, they performed as well as controls. From a practical standpoint, the implementation of motivational incentives in ADHD individuals is often a problem, however.

\title{
COMORBID ADHD/DEPRESSION TREATED WITH BUPROPION SR
}

A trial of bupropion sustained release (SR) was conducted in 24 adolescents (ages 11-16 years) with ADHD and either major depressive disorder or dysthymic disorder at the Department of Psychiatry, Dartmouth Medical School, Hanover, NH. The mean final titrated doses were $2.2 \mathrm{mg} / \mathrm{kg}$ qam and $1.7 \mathrm{mg} / \mathrm{kg}$ qpm, with a maximum of $3 \mathrm{mg} / \mathrm{kg}$ bid. Outcomes were rated by the clinician, parent, child, and teachers. Fourteen (58\%) showed a global improvement in both ADHD and depression on clinician ratings; the response was in depression only in $29 \%$. and in ADHD only in 4\%. Parents' and childrens' ratings of depression after bupropion improved significantly, when compared to prior placebo ratings. Parents' ratings of ADHD improved while teachers' ratings did not. Final parents' ratings of functional impairment showed significant improvements. All subjects completed the 2-week single-blind placebo lead-in and the 8 week bupropion trial. Comparing bupropion versus placebo periods, rash occurred in $13 \%$ vs $8 \%$; irritability in $8 \%$ vs $4 \%$; t tremor in $4 \%$ vs $0 \%$; and motor tics in $4 \%$ vs $0 \%$. No patient discontinued medication completely because of side effects. (Daviss WB, Bentivoglio P, Racusin R et al. Bupropion sustained release in adolescents with comorbid antention-deficit/hyperactivity disorder and depression. I Am Acad Child Adolesc Psychiatry March 2001;40:307-314). (Respond: Dr Daviss, Western Psychiatric Institute and Clinic, 3811 O'Hara St, Pittsburgh, PA 15213).

COMMENT. Bupropion SR may be effective in adolescents with depression and ADHD and further controlled studies are indicated. The teachers' failure to observe improvement in ADHD symptomatology is disappointing, and the occurrence of rash, irritability, tremor, and tics is noteworthy. The lack of seizures as a side effect in this study is encouraging, though the drug should be avoided or used with caution in patients with a predisposition to seizures. 